OPEN ACCESS

Edited by:

A. Gnanamani,

Central Leather Research Institute

(CSIR), India

Reviewed by:

Sandra R. R. Esteves,

University of South Wales,

United Kingdom

Kandasamy Saravanakumar, Kangwon National University,

South Korea

${ }^{*}$ Correspondence:

Richa Prasad Mahato

prasadricha333@gmail.com

Specialty section:

This article was submitted to

Microbiotechnology,

a section of the journal

Frontiers in Microbiology

Received: 01 June 2021 Accepted: 23 September 2021 Published: 15 October 2021

Citation:

Mahato RP, Kumar S and Singh P (2021) Optimization of Growth Conditions to Produce Sustainable Polyhydroxyalkanoate

Bioplastic by Pseudomonas aeruginosa EO1.

Front. Microbiol. 12:711588 doi: 10.3389/fmicb.2021.711588

\section{Optimization of Growth Conditions to Produce Sustainable Polyhydroxyalkanoate Bioplastic by Pseudomonas aeruginosa EO1}

\author{
Richa Prasad Mahato ${ }^{*}$, Saurabh Kumar ${ }^{2}$ and Padma Singh ${ }^{1}$ \\ ${ }^{1}$ Department of Microbiology, Kanya Gurukul Campus, Gurukul Kangri University, Haridwar, India, ${ }^{2}$ Molecular Bioprospection \\ Department, CSIR-Central Institute of Medicinal and Aromatic Plants, Lucknow, India
}

Polyhydroxyalkanoates (PHAs) are intracellularly synthesized by bacteria as carbonosomes that exhibit biodegradable thermoplastics and elastomeric properties. The use of cheaper edible oils as a source of carbon assists in the reduction of the production cost of such biopolyesters. In this work, different edible oils, such as groundnut oil (GNO), mustard oil, sesame oil, and soybean oil (SBO) were used to check their effect on PHA production from Pseudomonas aeruginosa EO1 (MK049902). Pseudomonas aeruginosa EO1 was used in a two-stage production system. In the first stage, bacterial growth was favored and, in the second, PHA was synthesized. GNO was found as the best carbon source for PHA production. The use of $2 \%(\mathrm{v} / \mathrm{v}) \mathrm{GNO}$, rich in saturated fatty acids, allowed PHA content of $58.41 \%$ and dry cell weight (DCW) of $10.5 \mathrm{~g} / \mathrm{L}$ at $\mathrm{pH} 7$ and temperature $35^{\circ} \mathrm{C}$ for $72 \mathrm{~h}$. Groundnut has a high potential for oil production and for the diversification of co-products with some potential of value aggregation. Such a perennial and sustainable species will almost certainly meet the criteria for becoming a significant commercial oilseed crop. Fourier transform infrared spectroscopy (FTIR) spectra showed strong characteristic bands at 1,282, 1,725, 2,935, 2,999, and 3,137 $\mathrm{cm}^{-1}$ for the PHA polymer. Gas chromatography-mass spectrometry (GC-MS) detects the presence of PHA copolymers.

Keywords: Pseudomonas aeruginosa, groundnut oil, biodegradable thermoplastic, FTIR, GC-MS

\section{INTRODUCTION}

Products that arise from synthetic plastic generate serious difficulties in solid waste disposal when dumped into the environment. However, it is difficult to decline the utilization of plastic products because of their versatile and widespread applications, but it is possible to explore the substitute of conventional petrochemical-based plastics with biodegradable biomaterials (Mohapatra et al., 2015). Nowadays, Biopolymers have focused much public and industrial attention due to great discussions searching for better waste-management plans (Doi, 1990). PHA are good members of biodegradable polyesters for the production of eco-friendly, biodegradable plastics. It is synthesized inside a diversity of microorganisms as a carbon and energy reserve, and its synthesis depends on environmental stress conditions e.g., a deficiency of nitrogen, phosphate, or oxygen (Lee, 1996a). The utilization of biodegradable 
polymers permits composting as a supplementary way for waste management. Polyhydroxyalkanoate (PHA) is an organic polyester with commercial properties, such as being eco-friendly, biodegradable, thermoplastic, and a biomaterial (Ramsay et al., 1990). Moreover, the utilization of these polymers connects with various other applications in medicine, agriculture, and industry. At least 75 genera of distinct Grampositive and Gram-negative bacteria have the ability to produce and accumulate intracellular natural polyesters, PHAs, as energy reserve material (Sangkharak and Prasertsan, 2008). To maintain their existence in a changing environment, many bacteria adopted a strategy of intracellular accumulation of storage polymers. PHA depositing capability is an example of this feature and generally indicates a short-termed abundance of carbon sources in contrast to other nutrients such as nitrogen and phosphorous (Steinbüchel et al., 1992). The prime hindrance for the commercialization and production schemes of PHAs is mainly the cost of the carbon substrate used. Bacteria could distribute into two groups according to their PHA accumulation strategies. The first group includes those bacteria that produce PHA when subjected to nutrient limitations, for instance, Ralstonia eutropha or Pseudomonas oleovorans. The second group includes the bacteria that do not need nutritional limitations for PHA synthesis during bacterial cell growth, for instance, Alcaligenes latus, A. vinelandii, Pseudomonas putida, c47T2, and $\mathrm{r}-\mathrm{E}$. coli (Lee, 1996a).

Plant oils, such as soybean, palm, and corn oil are suitable carbon substrates for PHAs synthesis because of their low cost compared to most sugars (Ciesielski et al., 2015). The theoretical yield of PHA production from fatty acids is $0.65 \mathrm{~g} / \mathrm{g}$, while the PHA yield from glucose ranges between 0.30 and $0.40 \mathrm{~g} / \mathrm{g}$ (Chanprateep, 2010). Carbohydrates, pure alkanes, and fatty acids are the common carbon substrates utilized in PHA production (Jiang et al., 2008). An average calculation for each tonne of polymer produced equals about three tons of glucose used (Collins, 1987). There could be various factors responsible for the higher PHA production by vegetable oils as (a) high carbon amount per unit mass in contrast to sugars (Chee et al., 2010) (b) the higher catabolism rate of lipid substrates (beta-oxidation at lipids; Muhr et al., 2013a,b); and (c) and the easy metabolization of saturated and unsaturated fats by microorganisms to produce PHAs (Koller et al., 2012).

In the discussion of PHAs synthesis, Pseudomonas sp. is one of the most studied bacteria (Jiang et al., 2008). Additionally, Pseudomonas shows a predominant and high growth rate even at a lower cost and, various substrates have been appreciated as good PHA producers. Pseudomonas aeruginosa usually

Abbreviations: \%, Percentage; ${ }^{\circ} \mathrm{C}$, Degree Celsius; $\mathrm{CHCl}_{3}$, Chloroform; DCW, Dry cell weight; EO, Edible oil; FE-SEM, Field emission scanning electron microscopy; FTIR, Fourier transform infrared spectroscopy; GC-MS, Gas chromatography-mass spectrometry; GNO, Groundnut oil; h, Hour; $\mathrm{HCl}$, Hydrochloric acid; mL, Milliliters; min, minute; MO, Mustard oil; MSM, Mineral salt medium; $\mathrm{NaOCl}$, Sodium hypochlorite; $\mathrm{NaOH}$, Sodium hydroxide; $\mathrm{NB}$, Nutrient broth; PHA, Polyhydroxyalkanoate; rpm, Rotation per minute; SO, Sesame oil; SBO, Soybean oil. produces medium chain length $(\mathrm{mcl})$ PHAs (Soberon-Chavez et al., 2005a). In this paper, we report: (1) The taxonomic classification of the P. aeruginosa strain EO1 (MK049902); (2) The PHA accumulation ability of $P$. aeruginosa strain EO1 utilizing edible oils; (3) and also describe the influence of nutritional conditions on its growth; and (4) characterization of produced PHA.

\section{MATERIALS AND METHODS}

\section{Bacteria and Culture Medium Used}

The strain EO1 used in this study was isolated from edibleoil-contaminated soil from the Haridwar district, India. The Tributyrine hydrolysis, Nile blue, and Sudan Black staining method was used for direct screening of bacteria that accumulate PHA. EO1 was characterized by colony characteristics, gram staining, and biochemical test as Pseudomonas sp. (Singh and Mahato, 2019).

The following were the components used in Mineral salt medium (MSM) for PHA production in $\mathrm{g} / \mathrm{L}: 20 \mathrm{ml} \mathrm{GNO}, 1.5 \mathrm{~g}$ $\mathrm{KH}_{2} \mathrm{PO}_{4}, 3.57 \mathrm{~g} \mathrm{Na}_{2} \mathrm{HPO}_{4}, 0.2 \mathrm{~g} \mathrm{MgSO}_{4} .7 \mathrm{H}_{2} \mathrm{O}, 1 \mathrm{~g}\left(\mathrm{NH}_{4}\right) \mathrm{SO}_{4}$, and $1 \mathrm{ml}$ trace element solution prepared following the previous procedure given by (Grothe et al., 1999).

\section{Molecular Identification of Isolated Bacteria}

16S rRNA sequencing was the molecular method used to identify PHA-producing bacteria carried out at Macrogen, Seoul, Korea. For this, genomic DNA was isolated using a Montage PCR product clean-up Kit. The $16 \mathrm{~S}$ rRNA gene was then amplified by universal eubacterial primers 27F and 1492R. 27F 5'AGAGTTTGATCMTGGCTCAG3' and 1492R 5'TACGGYTAC CTTGTTACGACTT3' primers proceeded the Forward and reverse DNA sequencing reaction of PCR amplicon. Thermal cycling consists of three steps: $95^{\circ} \mathrm{C}$ for $3 \mathrm{~min}$, followed by 30 cycles of $95^{\circ} \mathrm{C}$ for $30 \mathrm{~s}, 56^{\circ} \mathrm{C}$ for $30 \mathrm{~s}, 72^{\circ} \mathrm{C}$ for $45 \mathrm{~s}$, and a final step of $72^{\circ} \mathrm{C}$ for $10 \mathrm{~min}$. The PCR products had proceeded for sequencing. By following the manufacturer's instructions, the amplified DNA fragments were gel-purified utilizing QIA quickTM Gel Extraction Kit (Qiagen, United States) and sequenced by Macrogen Inc. (Seoul, Korea) using an ABI3730 XL Automatic DNA Sequencer (Applied Biosystems, Renton, United States). Finally, neighbor-joining was the method applied for phylogenetic tree construction on MEGA 7.0.20. References sequences with accession numbers were retrieved from GenBank and depicted on the phylogenetic tree (Tamura et al., 2013).

\section{Characterization of PHA Potent Bacteria by FE-SEM Analysis}

The difference between the PHA accumulating bacterial cells that grow in nutrient-deficient medium viz (MSM) and non-PHA accumulating bacterial cells that grew in nutrient-rich medium $v i z(\mathrm{NB})$ was observed by the Field Emission Scanning Electron Microscopy (FE-SEM). Firstly, extracted bacterial cells from NB and MSM were removed by phosphate-buffered saline 
(PBS), then fixed in 3\% glutaraldehyde solution overnight. The fixed bacterial cells were again washed in PBS to withdraw excess glutaraldehyde and sequentially dehydrated in 30,50 , 70, 80, and $100 \%$ ethanol. About $5 \mu \mathrm{l}$ of this bacterial cell suspension was sputter-coated with gold and analyzed in FE-SEM (Carl Zeiss Ultra Plus; Pillai et al., 2017).

\section{Effect of Growth Conditions for PHA Production}

Physicochemical parameters were enhanced for PHA production on different $\mathrm{pH}(6.0,7.0,8.0$, and 9.0), temperature $(25,30,35$, and $\left.40^{\circ} \mathrm{C}\right)$ and, incubation period $(24,48,72$, and $96 \mathrm{~h}$ ) by the bacteria on a production medium supplemented with MSM and containing Soybean oil (SBO), Groundnut oil (GNO), Sesame oil (SO), and Mustard oil (MO) as carbon substrates and ammonium sulfate, ammonium chloride, ammonium nitrate, and yeast extract as nitrogen sources incubated at $150 \mathrm{rpm}$ in the shaker (Lathwal et al., 2015). For the optimization process, $1 \%$ of bacterial inoculum was used. Experimental design includes three flasks for each optimization parameter. The $\mathrm{pH}$ of the medium was regulated by using $1 \mathrm{~N} \mathrm{HCl}$ or $\mathrm{NaOH}$. Then, the correlation of result via measuring the bacterial dry cell weight (DCW) and the extracted weight of PHA.

\section{Production of PHA Under Biphasic Growth Conditions}

Production studies of PHA were performed using $250 \mathrm{ml}$ Erlenmeyer flasks containing $100 \mathrm{ml}$ of mineral medium supplemented with groundnut oil (GNO) as carbon substrates at $2 \%$ concentration and ammonium sulfate as nitrogen source then sterilized the medium by autoclaving at $121^{\circ} \mathrm{C}$ for $20 \mathrm{~min}$. The separation of oil molecules was performed using a sonicator then shaking in an incubator so that bacteria were able to utilize it (Tufail et al., 2017). The activated culture of selected strains was inoculated at $4 \%(\mathrm{v} / \mathrm{v})$ into MSM for PHA synthesis. Fermentation was performed at $35^{\circ} \mathrm{C}$ under $150 \mathrm{rpm}$ for $72 \mathrm{~h}$. Then allow the flask for incubation at $37^{\circ} \mathrm{C}$. The $5 \mathrm{ml}$ of incubated medium was checked for bacterial DCW and PHA (Abid et al., 2016) at regular intervals of 12-96h from both the control and inoculated medium. The growth as indicated by DCW was plotted against time.

\section{Measurement of Dry Cell Weight}

Centrifuged the bacterial culture to measure the DCW at $8,000 \mathrm{rpm}$ for $15 \mathrm{~min}$ and, the pellet was oven-dried at $55^{\circ} \mathrm{C}$ to obtain constant weight followed to the cooling and then finally recording the weight (Basavaraj et al., 2013). Determination of the bacterial DCW by subtracting the filter paperweight from the filter paperweight plus the cells. Calculation of the bacterial DCW was by using the formula:

$$
\mathrm{DCW}=W 2-W 1
$$

Where W2 is the final dry weight of filter paper with cell pellet and $W 1$ is the initial dry weight of filter paper without pellet (Abid et al., 2016).

\section{Recovery of PHA}

The extraction of the polymer for the quantitative screening of PHA was carried out by inoculating $5 \%$ pre-culture broth in $100 \mathrm{ml}$ of MSM medium for $72 \mathrm{~h}$ of incubation at $35^{\circ} \mathrm{C}$. Then $10 \mathrm{ml}$ of MSM culture was centrifuged at $8,000 \mathrm{rpm}$ for $15 \mathrm{~min}$, resulting in the formation of the pellet, the cell pellet was incubated at $50^{\circ} \mathrm{C}$ for $1 \mathrm{~h}$ in sodium hypochlorite $(\mathrm{NaOCl})$. To obtain cell extract, a cell pellet containing $(10 \mathrm{ml})$ sodium hypochlorite was centrifuged at $12,000 \mathrm{rpm}$ for $30 \mathrm{~min}$ after incubation at $50^{\circ} \mathrm{C}$ for $1 \mathrm{~h}$.

The $\mathrm{NaOCl}$ containing cell pellet was serially washed through distilled water to remove bleach solution, acetone to remove low molecular weight lipid, and absolute ethanol. After this, the washed pellet was dissolved in $10 \mathrm{ml}$ of $\mathrm{CHCl}_{3}$ and incubated overnight at $50^{\circ} \mathrm{C}$ and was dried at room temperature and kept at $4^{\circ} \mathrm{C}$ and weighed (Singh et al., 2013). Calculation of the PHA\% was via the below formula.

$$
\begin{aligned}
& \text { PHA production }(\%) \\
& =\frac{\text { Dry weight of extracted PHA }(\mathrm{g} / \mathrm{L})}{\mathrm{DCW}(\mathrm{g} / \mathrm{L})} \times 100
\end{aligned}
$$

\section{Determination of PHA Content and Monomer Composition FTIR Spectrophotometer Analysis of PHA}

A $1 \mathrm{mg}$ extracted sample of PHA was mixed with $\mathrm{KBr}$. The polymer sample was analyzed by the Fourier transform infrared spectroscopy (FTIR) in the range $4,000-450 \mathrm{~cm}^{-1}$ (Mattson1000 model; Getachew and Woldesenbet, 2016).

\section{GC-MS Analysis of PHA}

Polyhydroxyalkanoate content was determined by methanolysis of monomers according to the previously mentioned method by Shamala et al. (2009). The $10 \mathrm{mg}$ cells were exposed to methanolysis in $1 \mathrm{ml}$ chloroform, $0.85 \mathrm{ml}$ methanol, and $0.15 \mathrm{ml}$ concentrated $\mathrm{H}_{2} \mathrm{SO}_{4}$ at $100^{\circ} \mathrm{C}$ for $140 \mathrm{~min}$. Homogenization of the samples with deionized water and used the bottom organic phase for GC analysis (Shimadzu GC-MS QP 2010 Plus). Identification of compounds was using the NIST14 library (Ansari and Fatma, 2016).

\section{RESULTS AND DISCUSSION}

\section{Genotypic Characterization}

Bacterial isolate $P$. aeruginosa $\mathrm{EO} 1$ was investigated for its taxonomic position. Representation of the species was established upon sequencing of most of the $16 \mathrm{~S}$ rRNA gene. The closest Pseudomonads strains showed about $98-100 \%$ of shared sequence identity with EO1. On analysis of the constructed phylogenetic tree, it was interesting to note that the strain $P$. aeruginosa (EO1) was close to strain KF574910.1 (Figure 1). The analysis of the 16S rRNA gene sequences data for the strain P. aeruginosa EO1 shares the same sequence but slightly differs from other Pseudomonas species. The partial 16S rRNA sequence of the 


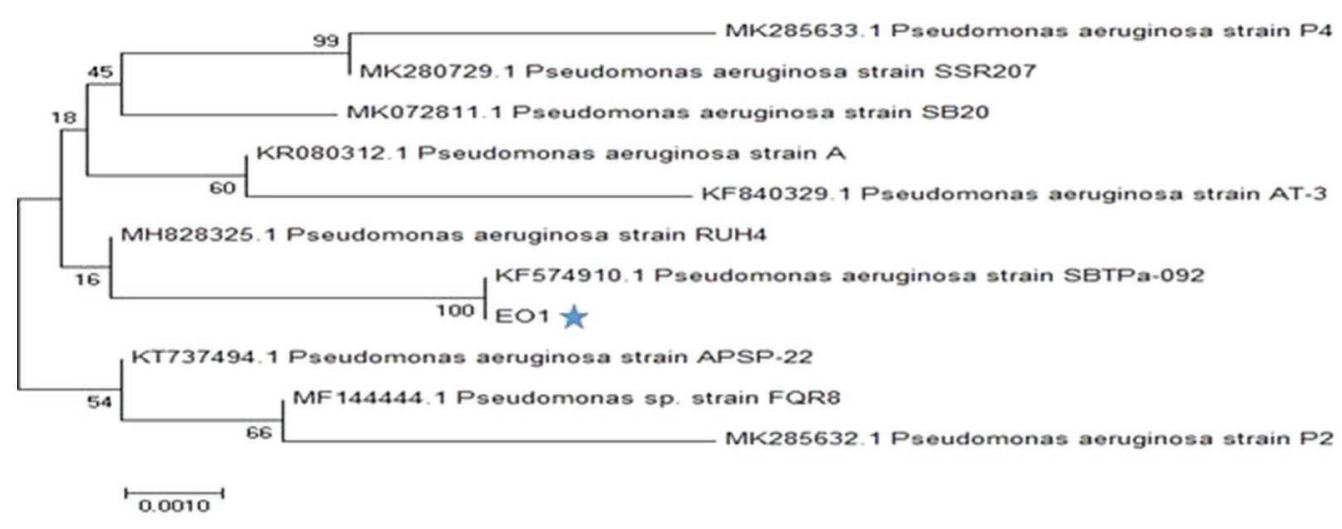

FIGURE 1 | Phylogenetic tree of bacterial strain EO1 Neighbor-joining tree based on 16S rRNA gene sequences showing phylogenetic relationship between strain Pseudomonas aeruginosa EO1 and closely related taxa of the genus $P$. aeruginosa.
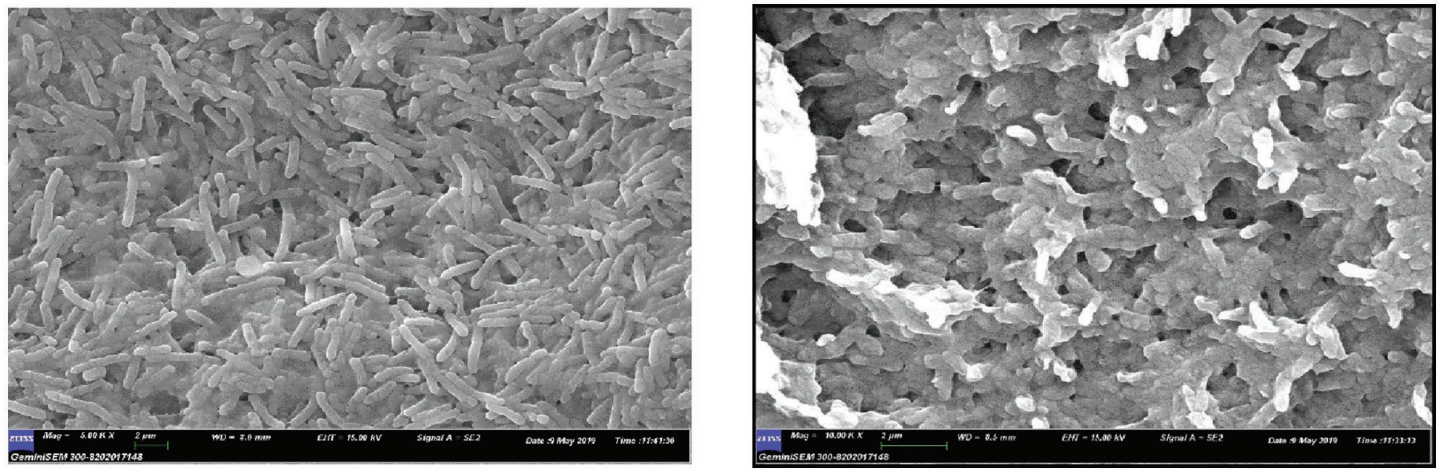

FIGURE 2 | Field Emission Scanning Electron Microscopy (FE-SEM) image analysis of $P$. aeruginosa EO1 grown on NB (Left hand) $P$. aeruginosa EO1 grown on MSM (Right hand).

bacteria to has been submitted to the NCBI gene bank (Accession no. MK049902). Much attempts on research work in this regard by using $P$. aeruginosa for the economical production of PHA, which represents the most common PHA (Aremu et al., 2011; Tripathi et al., 2012; Patel, 2014). The reason could be the predominance of Pseudomonas in nature, and its high growth rate even on cheap and distinct substrates. Pseudomonas species are characterized by their ability to utilize and degrade a variety of carbon sources due to their wide catabolic versatility and genetic diversity. For these reasons, they are a natural choice regarding techniques of in situ and ex situ bioremediation (Kahlon, 2016).

\section{Characterization of PHA Producing Bacterial Cell by FE-SEM}

Field Emission Scanning Electron Microscopy was carried out to detect the PHA accumulating bacterial cells. It indicated that the bacterial cells grown on MSM were large in size and of greater weight while NB-grown cells were of normal shape (Figure 2). In this regard, Lee (1996b) indicated in his work that the bacterial cells grown on MSM were large in size and of greater weight while NB-grown cells were normal in shape. Similar findings were also obtained in previous research by (Bhagowati et al., 2015) that revealed the rod-shaped morphology and a minor rise in the size of isolates after 3 days of incubation in Minimal Davis broth under SEM examination. At the optimal growth conditions for $B$. cereus SE-1 using maltose as the only carbon source, cell mass, and PHB accumulation increased with increasing incubation time.

\section{Influence of Physical Parameters on PHA Production}

The physical growth conditions play a critical role in biomass as well as PHA production. Thus, we optimized the physical growth conditions for PHA production. Figure 3 depicts that bacteria had grown at a vast range of $\mathrm{pH}(5,6,7$, and 8$)$ and, the maximum polymer accumulation (58.16\%) was at $\mathrm{pH}$ 7. This finding is similar to the early reporting for PHA production at $\mathrm{pH} 7$ by Bacillus subtilis (Mohapatra et al., 2015). The lower polymer synthesis at extremes of $\mathrm{pH}(>7$ and $<7)$ values is because degradative enzymes break down the polymer so that $\mathrm{PHB}$ is utilizing at a rate almost equal to its synthesis rate (Flora et al., 2010). 


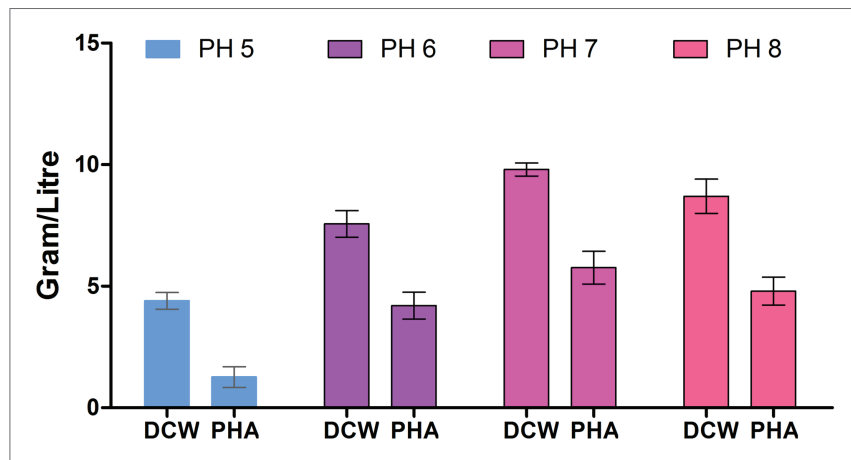

FIGURE 3 | Effect of pH on polyhydroxyalkanoate (PHA) production by P. aeruginosa EO1.

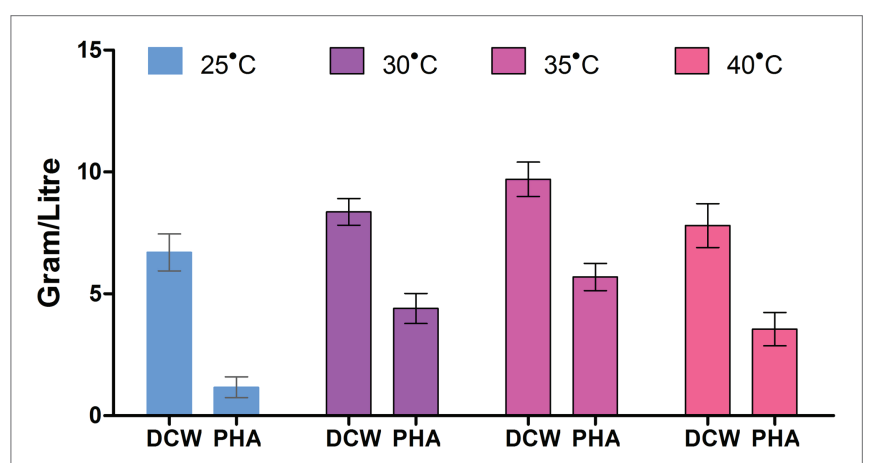

FIGURE 4 | Effect of temperature on PHA production by P. aeruginosa EO1.

The influence of varying incubation temperatures $(25,30$, 35 , and $40^{\circ} \mathrm{C}$ ) was checked, and a maximum of $58.3 \%$ of PHA was at the temperature $35 \pm 2{ }^{\circ} \mathrm{C}$ (Figure 4). The PHA accumulation was found to be low at the extremes of the temperature range i.e., $\left(>15^{\circ} \mathrm{C}\right.$ and $\left.<50^{\circ} \mathrm{C}\right)$. This response was probably due to the declining activity of enzymes involved in the biosynthesis of PHA at these temperatures. The variation in the temperature could create a change in PHA content, or could be since extreme temperatures minimize the metabolic activity (enzyme activity) of microorganisms, and that ultimately decreases the strength of their PHA production (Noha et al., 2013).

The PHA production by strain EO1 was observed by growth in a production medium from $24,48,72$, and $96 \mathrm{~h}$ of incubation. PHA accumulation was observed at a maximum of $58.41 \%$ at $72 \mathrm{~h}$. Enhancement in PHA production occured up to $72 \mathrm{~h}$ $(5.9 \mathrm{~g} / \mathrm{L})$ of stationary growth phase conditions and, after that, a reduction of $3.96 \mathrm{~g} / \mathrm{L}$ was observed after $72 \mathrm{~h}$ (Figure 5) due to the intracellular utilization of the PHA as energy reserves and a carbon source, while a hike in metabolites also reduced PHA production (Bhuwal et al., 2013). Regarding the determination of bacterial growth rate and the amount of PHA after $48 \mathrm{~h}$ of incubation, with each progressive day the bacteria showed various growth rates. The growth relationship on each day was not linear, as the maximum bacterial growth was on the 3rd day of incubation due to the highest density of bacteria.
Our results supported the previous findings as the maximum PHA accumulated at $72 \mathrm{~h}$ of incubation in Pseudomonas sp. (Lathwal et al., 2015). The reason for the reduction in PHA was bacteria using PHA as a carbon source because of nutrient deficiency in the growth medium. Maximum PHA production was observed in isolate $\mathrm{AWW}$ at a $\mathrm{pH}$ range of 7.0 and temperature $37^{\circ} \mathrm{C}$ after $48 \mathrm{~h}$ (Getachew and Woldesenbet, 2016).

The influence of four edible oils on PHA production by the bacteria was studied to select the best and most economical one. SBO, GNO, SO, and MO are among the four major vegetable oils produced globally. The GNO was the best carbon source for bacterial growth as it gave $(10.1 \mathrm{~g} / \mathrm{L})$ of PHA (Figure 6). On the other hand, GNO was also the best carbon source for PHAs production $(58.41 \%)$, followed by SO (40.40\%), and MO (31.7\%). SBO (27.36\%) was the worst carbon source for polymer production. It may be due to the composition of GNO, as it has been reported previously that Peanut oil contains a high concentration of saturated fatty acids (17\%) compared to soybean oil (14\%) and canola oil (13\%; Vassiliou et al., 2009; PérezArauz et al., 2019). The organism exhibits maximum cell growth as it has a selective preference for the carbon source. The reason behind this is a genetic makeup that leads to the metabolism of a specific carbon feed (Ashby and Foglia, 1998).

Ruiz et al. (2019) studied the effect of hydrolyzed waste cooking oil fatty acids (HWCOFA) that showed HWCOFA could be used as the sole substrate for PHA production by P. putida KT2440. Glucose was also a suitable substrate for PHA production (Mohapatra et al., 2015).

Polyhydroxyalkanoate was produced by the strain EO1 supplemented with four different nitrogen sources (ammonium sulfate, ammonium chloride, ammonium nitrate, and yeast extract), and the identified best carbon source, namely GNO, as illustrated in Figure 7. Out of the four nitrogen sources, ammonium sulfate supported the highest PHA production; giving the maximum PHA accumulation observed by strain EO1 $(5.1 \mathrm{~g} / \mathrm{L})$. This was followed by ammonium chloride $(4.3 \mathrm{~g} / \mathrm{L})$, ammonium nitrate $(3.92 \mathrm{~g} / \mathrm{L})$, and the poorest PHA accumulation was by Yeast extract $(3.46 \mathrm{~g} / \mathrm{L})$.

Previous work reported that out of four nitrogen sources (ammonium chloride, ammonium sulfate, ammonium nitrate, and urea), the highest cell dry mass and PHA level by Alcaligenes latus ATCC 29714 (or DSM 1123) was also gained with ammonium sulfate as the nitrogen source (Grothe et al., 1999). Previous work has shown PHA production when utilizing various nitrogen sources (Lathwal et al., 2015). It was noticed that ammonium sulfate increased the yield of PHB produced by strain KS-3. There might be a reason for this in the relatively low nitrogen concentration of ammonium sulfate resulting in an increased $\mathrm{C} / \mathrm{N}$ ratio, which stimulated an increase $\mathrm{PHB}$ synthesis. The least DCW and PHB accumulation were achieved with yeast extract (Basavaraj et al., 2013; Getachew and Woldesenbet, 2016).

\section{Production and Extraction of Polymer for Estimation of PHA}

Among various physicochemical parameters, $\mathrm{pH} 7$ and temperature $35^{\circ} \mathrm{C}$ over the incubation period of $72 \mathrm{~h}$ was found 


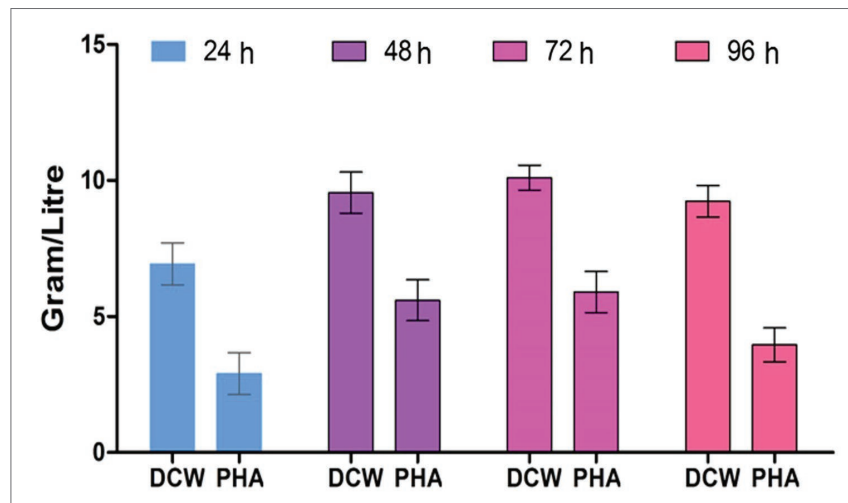

FIGURE 5 | Effect of incubation period on PHA production by $P$. aeruginosa EO1.

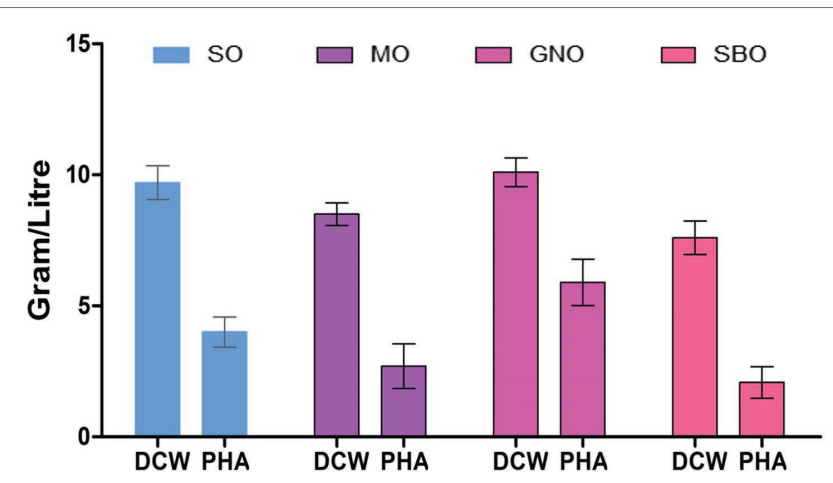

FIGURE 6 | Effect of different carbon sources on PHA production by P. aeruginosa EO1.

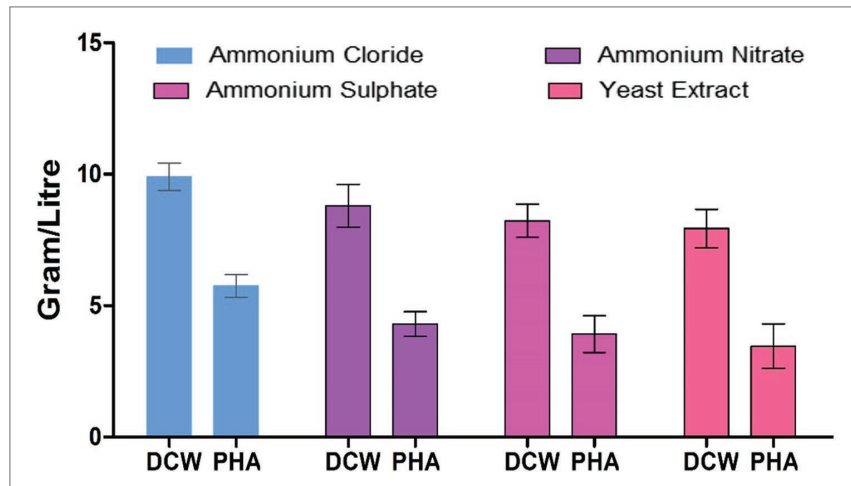

FIGURE 7 | Effect of different nitrogen sources on PHA production by $P$. aeruginosa EO1.

optimum for maximum PHA production by optimizing different culture conditions. The PHA was extracted from the cell by the hypochlorite and chloroform method as described above. The bacteria exhibited maximum PHA accumulation in MSM $(6.1 \mathrm{~g} / \mathrm{L})$ from $10.5 \mathrm{~g} / \mathrm{L}$ (DCW) under optimized culture conditions and in the presence of the best carbon substrate. Maximum DCW and PHA by isolate EO1 were gained at $\mathrm{pH} 7$ and $72 \mathrm{~h}$ of incubation in shaken flask culture cultivation. The PHA accumulation was initiated at the initial log phase and continued up to $72 \mathrm{~h}$ of incubation. The deficiency of nitrogen and the existence of a carbon source enhanced PHA productivity.

Different strains of Pseudomonas have been reported previously for PHA production using oily substrates. For e.g., Pseudomonas sp. DR2 synthesizes PHAMCL up to $23.53 \%$ (w/w) using waste vegetable oil (Song et al., 2008). PHA $(50.27 \% \mathrm{w} / \mathrm{w})$ of the total CDM produced by utilizing soybean oil (Abid et al., 2016). Corn oil serves as a carbon source for bacterial growth and supports cells to synthesize PHA up to $35.63 \%$ (Chaudhary et al., 2010). Comparable results were reported by Haba et al. (2007) as P. aeruginosa synthesizes PHAs up to $36 \%(w / w)$ of the cell dry mass.

\section{FTIR Analysis of PHA}

Polymer obtained after extraction was applied to record IR spectra in the range between 4,000 and $450 \mathrm{~cm}^{-1}$ (Figure 8). IR spectra indicated strong absorption bands at 2,935, 2,999, and $3,137 \mathrm{~cm}^{-1}$ were because of the $\mathrm{C}-\mathrm{H}$ stretching vibrations of methyl and methylene groups. The absorption bands at 1,283 and $1,726.42 \mathrm{~cm}^{-1}$ revealed specificity for $\mathrm{C}-\mathrm{O}$ and ester group $(\mathrm{C}=\mathrm{O})$ stretching vibrations. The peaks ranging between 2,848.77-3,008.35 $\mathrm{cm}^{-1}$ indicated the existence of $\mathrm{CH}_{3^{-}},-\mathrm{CH}_{2^{-}}$ $-\mathrm{CH}_{2-}$, and $-\mathrm{CH}_{2}-\mathrm{CH}_{3}$ (Gumel et al., 2014; Abid et al., 2016). Figure 6 showed that the absorption band on $1,726 \mathrm{~cm}^{-1}$ indicated the PHA marker band appropriated for carbonyl $\mathrm{C}=\mathrm{O}$ stretches of the ester group detected in the chain of exceedingly arranged crystalline structures (Randriamahefa et al., 2003).

The FTIR result of this study was matched with any prior studied FTIR spectrum of PHA such as Muralidharan and Radha (2014), which had shown two strong absorption peaks of $\mathrm{PHB}$ at $1,724.2$ and $1,280.3 \mathrm{~cm}^{-1}$, matching to $-\mathrm{C}=\mathrm{O}$ and -C-O stretching groups. Bacillus megaterium uyuni S29 was used for PHA production and PHA was characterized by IR transmission spectrum. It exhibited main bands at $1,726,2,960-2,850, \quad 1,390-1,370$, and $1,230-1,050 \mathrm{~cm}^{-1}$ corresponding to the carbonyl group, methyl and methylene groups, the methyl group, and the ester group, respectively. The absorption band $1,385.56 \mathrm{~cm}^{-1}$ was allocated to the terminal $\mathrm{CH}_{3}$ groups and the same group mentioned in the literature at $1,378.83 \mathrm{~cm}^{-1}$ (Reddy et al., 2008). The peaks near $1,726,2,935,2,999$, and $1,058.62 \mathrm{~cm}^{-1}$ confirmed that mcl-PHA copolymer developed because of the variation in the peaks near $2,900 \mathrm{~cm}^{-1}$ of pure $\mathrm{PHB}$ and bacterial synthesized PHAs (Hong et al., 1999; Kim et al., 2007; Khare et al., 2014). These important absorption bands confirmed the structure of mcl-PHA.

\section{GC-MS Analysis of PHA}

Polyhydroxyalkanoate extracted from $P$. aeruginosa strain EO1 using GNO significantly contained (3HB) Betahydroxybutyric acid methyl ester (7.41\%), (3HDD) Methyl 3-hydroxytetradecanoate (7.26\%), and (3HD) hexadecanoic acid, methyl ester $(5.03 \%)$. These compounds proved that 


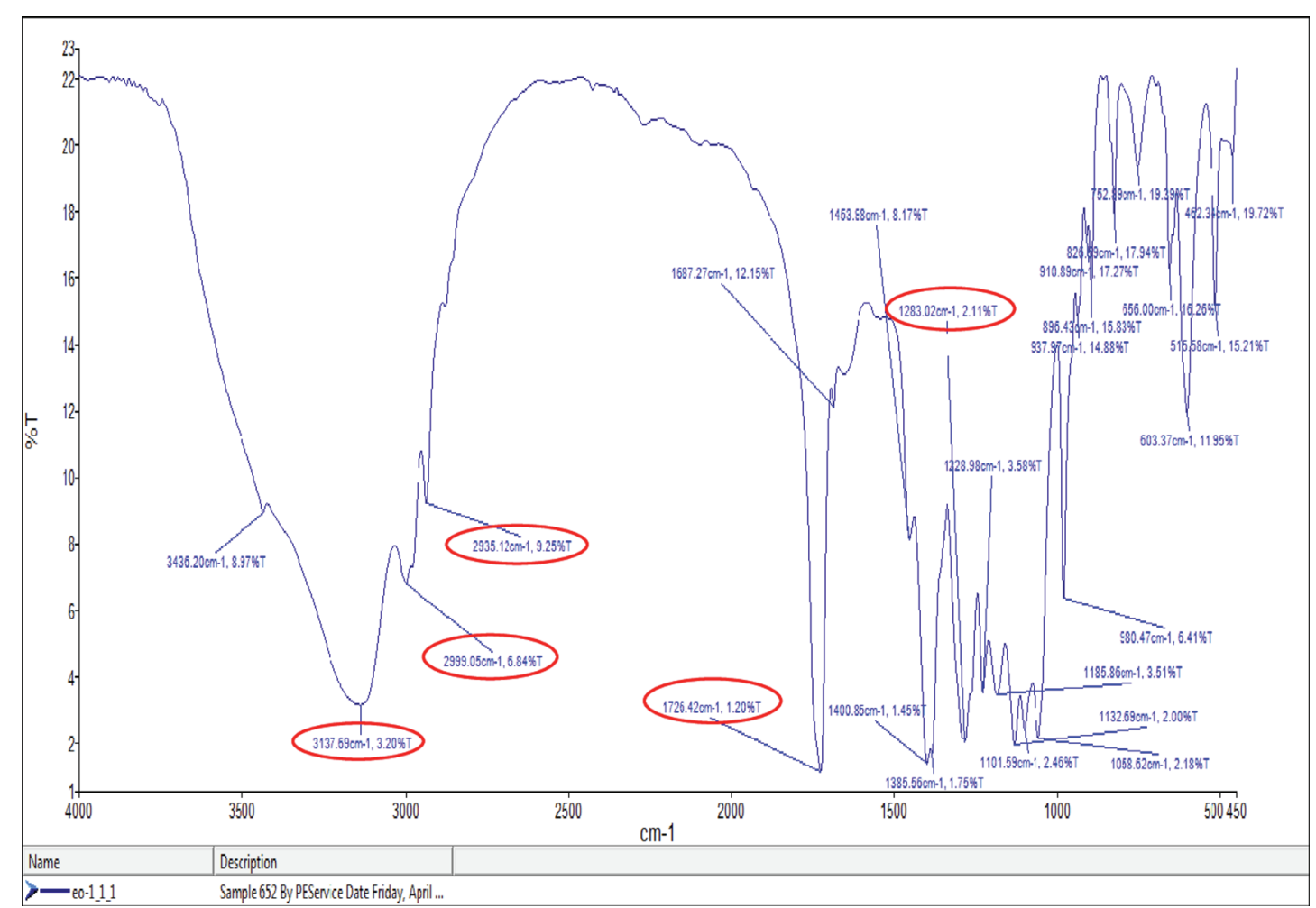

FIGURE 8 | Fourier transform infrared spectroscopy (FTIR) spectra of extracted polymer from P. aeruginosa EO1.

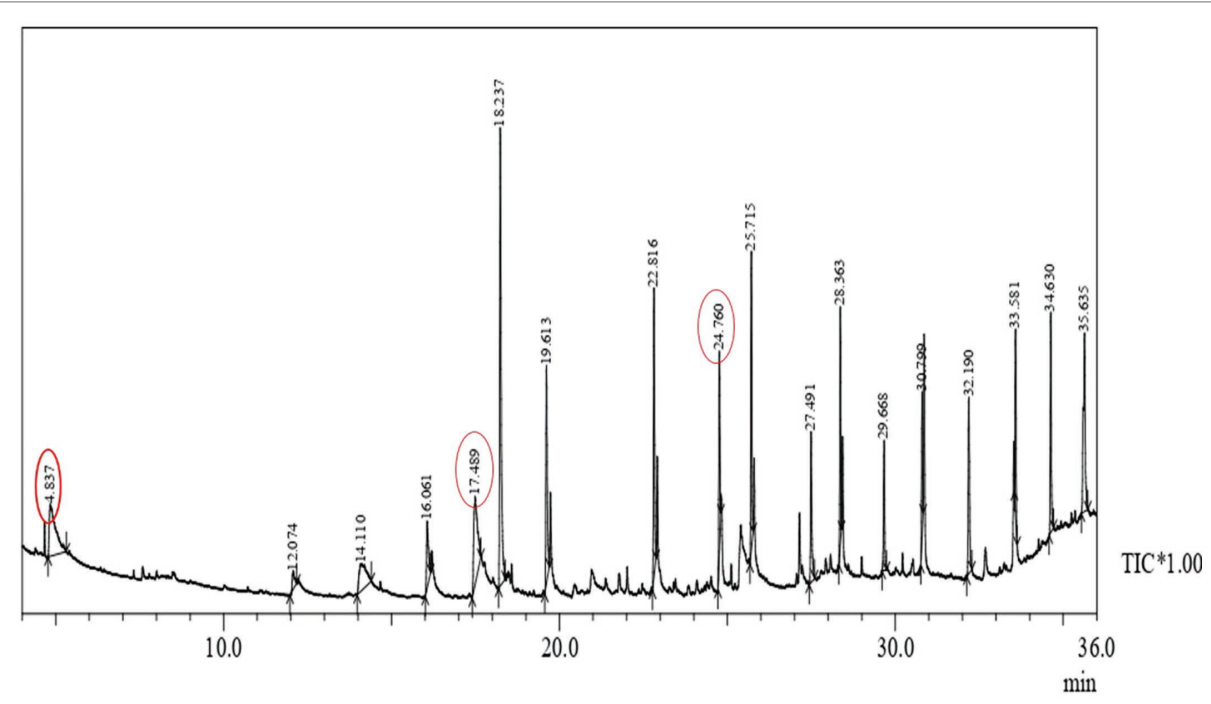

FIGURE 9 | Gas chromatography-mass spectrometry (GC-MS) of extracted polymer from P. aeruginosa EO1.

monomer chains were constructed of a biodegradable polyester family. It is visualized in Figure 9 that the usual molecular fragment of the $3 \mathrm{HB}$ ion chromatogram of the $\mathrm{PHB}$ developed here. A predominant peak indicated the tetramer of $3 \mathrm{HB}$ (Beta-hydroxybutyric acid), Methyl 3-hydroxy-tetra decanoate, hexadecanoic acid, and methyl ester were observed at 4.837,
7.26, and, $5.03 \mathrm{~min}$, respectively. The PHA of molecular weight $(118 \mathrm{kDa})$ was obtained from $P$. aeruginosa strain EO1 after the GC-MS analysis. About $177 \mathrm{kDa}$, molecular weight of the PHB was recovered by Galego et al. (2000). This drop-down of molecular weight was because of distinct polyhydroxyalkanoic acids, e.g., $3 \mathrm{HV}$ and $3 \mathrm{HBV}$ up to a 
low percentage $(32 \%)$ with the major polymer $3 \mathrm{HB}$. Due to their potential to synthesize mcl-PHA from distinct carbon substrates, Fluorescent pseudomonads are studied well (Huisman et al., 1989; Sun et al., 2007; Goh and Tan, 2012).

\section{CONCLUSION}

Wide production, commercialization, and thus practical application of PHAs as a biodegradable alternative to conventional plastics is still limited due to high production costs. Plant oils provide an excellent substrate for bacterial growth and PHA production. However, PHA productivity from these substrates needs to be improved in order to progress such processes toward commercial scale and application by optimizing physicochemical conditions, as these substrates are less costly and more readily scaled. As shown in the present study, all four of the edible oils have tested have potential for PHA production. In the present study, we reported PHA production by $P$. aeruginosa EO1 strain. In the study, the edible oils were used as a source of carbon for P. aeruginosa EO1 mediated production of PHA. In addition, we optimized the physicochemical conditions for high yield. Further, the PHA production was confirmed through FTIR spectroscopy and GC-MS analysis. So, we conclude that the $P$. aeruginosa EO1 strains used in this study could successfully utilize cheaply available GNO as the sole carbon source and produced a high level of PHA in flask cultures under optimized culture conditions. Those features will

\section{REFERENCES}

Abid, S., Raza, Z. A., and Hussain, T. (2016). Production kinetics of polyhydroxyalkanoates by using Pseudomonas aeruginosa gamma ray mutant strain EBN-8 cultured on soybean oil. 3 Biotech. 6:142. doi: 10.1007/s13205-016-0452-4

Ansari, S., and Fatma, T. (2016). Cyanobacterial polyhydroxybutyrate (PHB): screening, optimization and characterization. PLoS One 11:e0158168. doi: 10.1371/journal.pone.0158168

Aremu, M. O., Aransiola, E. F., Layokun, S. K., and Solomon, B. O. (2011). Production of polyhydroxybutyrate (PHB) by Pseudomonas putida strain KT2440 on cassava hydrolysate medium. Res. J. Chem. Sci. 1, 67-73.

Ashby, R. D., and Foglia, T. A. (1998). Poly(hydroxyalkanoate) biosynthesis from triglyceride substrates. Appl. Microbiol. Biotechnol. 49, 431-437. doi: $10.1007 / \mathrm{s} 002530051194$

Basavaraj, H., Shyama, P. P., and Mohammed, S. (2013). Production of polyhydroxybutyrates from Paenibacillus durus $B V-1$ isolated from oil mill soil. J. Microb. Biochem. Technol. 5, 1948-5948. doi: 10.4172/1948-5948.1000092

Bhagowati, P., Pradhan, S., Dash, H. R., and Das, S. (2015). Production, optimization and characterization of polyhydroxybutyrate, a biodegradable plastic by bacillus spp. Biosci. Biotechnol. Biochem. 79, 1454-1463. doi: 10.1080/09168451.2015.1034651

Bhuwal, A. K., Singh, G., Aggarwal, N. K., Goyal, V., and Yadav, A. (2013). Isolation and screening of polyhydroxyalkanoates producing bacteria from pulp. Paper, and cardboard industry wastes. Int. J. Biomater. 2013:752821. doi: $10.1155 / 2013 / 752821$

Chanprateep, S. (2010). Current trends in biodegradable polyhydroxyalkanoates. J. Biosci. Bioeng. 110, 621-632. doi: 10.1016/j.jbiosc.2010.07.014

Chaudhary, W. N., Jamil, N., and Ali, I. (2010). Screening for Polyhydroxyalkanoate (PHA) producing bacterial strains and comparison of PHA production from various inexpensive carbon sources. Ann. Microbiol. 61, 623-629. doi: 10.1007/ s13213-010-0181-6 significantly contribute to PHA cost reduction and minimize the requirements for expensive sugar as a carbon substrate.

\section{DATA AVAILABILITY STATEMENT}

The datasets presented in this study can be found in online repositories. The names of the repository/repositories and accession number can be found at: NCBI (accession: MK049902).

\section{AUTHOR CONTRIBUTIONS}

RM performed the experiments. RM and SK analyzed the data. RM and PS conceived the idea and wrote the manuscript. All authors contributed to the article and approved the submitted version.

\section{ACKNOWLEDGMENTS}

The authors gratefully acknowledge financial support to the Department of Microbiology, Kanya Gurukul Girls Campus, Gurukul Kangri University, Haridwar, India, and Ajay Kumar, JNU, New Delhi for his help with data acquisition using GC-MS, Macrogen, Seoul, South Korea for the molecular sequencing, The IIC for FE-SEM and Department of Chemistry IIT, Roorkee for the FTIR analysis.

Chee, J. Y., Yoga, S. S., Lau, N. S., Ling, S. C., Abed, R. M., and Sudesh, K (2010). "Bacterially produced polyhydroxyalkanoate (PHA): converting renewable resources into bioplastics," in Current Research, Technology and Education Topics in Applied Microbiology and Microbial Biotechnology. Vol. 2. eds. A. mendez-Vilas, 1395-1404.

Ciesielski, S., Możejko, J., and Pisutpaisal, N. (2015). Plant oils as promising substrates for polyhydroxyalkanoates production. J. Clean. Prod. 106, 408-421. doi: $10.1016 /$ j.jclepro.2014.09.040

Collins, S. (1987). Choice of substrate in Polyhydroxybutyrate synthesis. Spec. Publ. Soc. General Microbiol. 21, 161-168.

Doi, Y. (1990). Microbial Polyesters. Weinheim, Cambridge, New York: VCH Publisher

Flora, G., Bhatt, K., and Tuteja, U. (2010). Optimization of culture conditions form poly Â-Hydroxybutyrate production From isolated bacillus species. J. Cell Tissue Res. 10, 2235-2242.

Galego, N., Rozsa, C., Sánchez, R., Fung, J., Vázquez, A., and Tomás, J. S. (2000). Characterization and application of poly ( $\beta$-hydroxyalkanoates) family as composite biomaterials. Polym. Test. 19, 485-492. doi: 10.1016/S0142-9418 (99)00011-2

Getachew, A., and Woldesenbet, F. (2016). Production of biodegradable plastic by polyhydroxybutyrate (PHB) accumulating bacteria using low cost agricultural waste material. BMC. Res. Notes 9:509. doi: 10.1186/s13104-016-2321-y

Goh, Y. S., and Tan, I. K. P. (2012). Polyhydroxyalkanoate production by Antarctic soil bacteria isolated from Casey station and Signy Island. Microbiol. Res. 167, 211-219. doi: 10.1016/j.micres.2011.08.002

Grothe, E., Moo-Young, M., and Chisti, Y. (1999). Fermentation optimization for the production of poly(beta-hydroxybutyric acid) microbial thermoplastic. Enzym. Microb. Technol. 25, 132-141. doi: 10.1016/S0141-0229(99) 00023-X

Gumel, A. M., Annuar, M. S. M., and Heidelberg, T. (2014). Growth kinetics, effect of carbon substrate in biosynthesis of mcl-PHA by Pseudomonas putida Bet001. Braz. J. Microbiol. 45, 427-438. doi: 10.1590/S1517-83822014000200009 
Haba, E., Vidal-Mas, J., Bassas, M., Espuny, M. J., Llorens, J., and Manresa, A. (2007). Poly 3-(hydroxyalkanoates) produced from oily substrates by Pseudomonas aeruginosa 47T2 (NCBIM 40044): effect of nutrients and incubation temperature on polymer composition. Biochem. Eng. J. 35, 99-106. doi: 10.1016/j.bej.2006.11.021

Hong, K., Sun, S., Tian, W., Chen, G. Q., and Huang, W. (1999). A rapid method for detecting bacterial polyhydroxyalkanoates in intact cells by Fourier transform infrared spectroscopy. Appl. Microbiol. Biotechnol. 51, 523-526. doi: 10.1007/s002530051427

Huisman, G. W., de Leeuw, O., Eggink, G., and Witholt, B. (1989). Synthesis of poly-3-hydroxyalkanoates is a common feature of fluorescent pseudomonads. Appl. Environ. Microbiol. 55, 1949-1954. doi: 10.1128/aem.55.8.1949-1954.1989

Jiang, Y., Song, X., Gong, L., Li, P., Dai, C., and Shao, W. (2008). High poly ( $\beta$-hydroxybutyrate) production by Pseudomonas fluorescens A2a5 from inexpensive substrates. Enzym. Microb. Technol. 42, 167-172. doi: 10.1016/j. enzmictec.2007.09.003

Kahlon, R.S. (2016). Pseudomonas: Molecular and Applied Biology. Berlin, Germany: Springer

Khare, E., Chopra, J., and Arora, N. K. (2014). Screening for mcl-PHA producing fluorescent pseudomonads and comparison of mcl-PHA production under iso-osmotic conditions induced by PEG and $\mathrm{NaCl}$. Curr. Microbiol. 68, 457-462. doi: 10.1007/s00284-013-0497-0

Kim, D. Y., Kim, H. W., Chung, M. G., and Rhee, Y. H. (2007). Biosynthesis, modification, and biodegradation of bacterial medium chain length polyhydroxyalkanoates. J. Microbiol. 45, 87-97

Koller, M., Salerno, A., Muhr, A., Reiterer, A., and Braunegg, G. (2012). Polyhydroxyalkanoates: biodegradable polymers and plastics from renewable resources. Mater. Technol. 46, 23-30.

Lathwal, P., Nehra, K., Singh, M., and Jamdagni, P. (2015). Optimization of culture parameters for maximum polyhydroxybutyrate production by selected bacterial strains isolated from rhizospheric soils. Pol. J. Microbiol. 64, 227-239. doi: $10.5604 / 01.3001 .0009 .2118$

Lee, S. Y. (1996a). Review: bacterial polyhydroxyalkanoate. Biotechnol. Bioeng. $49,1-14$.

Lee, S. Y. (1996b). Plastic bacteria? Progress and prospects for polyhydroxyalkanoate production in bacteria. Trends Biotechnol. 14, 431-438.

Mohapatra, S., Mohanta, P. R., Sarkar, B., Daware, A., Kumar, C., and Samantaray, D. P. (2015). Production of polyhydroxyalkanoates (PHAs) by Bacillus strain isolated from waste water and its biochemical characterization. Proc. Natl. Acad. Sci., India, Sect. B. Biol. Sci. 87, 459-466. doi: 10.1007/s40011-015-0626-6

Muhr, A., Rechberger, E. M., Salerno, A., Reiterer, A., Malli, K., Strohmeier, K., et al. (2013b). Novel description of mcl-PHA biosynthesis by pseudomonas chlororaphis from animal-derived waste. J. Biotechnol. 165, 45-51. doi: 10.1016/j. jbiotec.2013.02.003

Muhr, A., Rechberger, E. M., Salerno, A., Reiterera, A., Margaretha, S., Kwiecień, M., et al. (2013a). Biodegradable latexes from animal-derived waste: biosynthesis and characterization of mcl-PHA accumulated by Ps. Citronellolis. React. Funct. Polym. 73, 1391-1398. doi: 10.1016/j.reactfunctpolym. 2012.12.009

Muralidharan, R., and Radha, K. V. (2014). Growth and biological production of polyhydroxy butyrate (PHB) by bacillus megaterium MTCC 8075. J. Chem. Biol. Phys. Sci. 4, 1271-1279.

Noha, S. E., Khaled, M. A., Mohammad, M. A., and Nadia, A. H. (2013). Optimizations of bioplastic (poly- $\beta$-hydroxybutyrate) production by a promising Azomonas macrocytogenes bacterial isolate P173. Afr. J. Microbiol. Res. 43, 5025-5035. doi: 10.5897/AJMR2013.6060

Patel, S. S. (2014). Production of polyhydroxybutyrate using agro-industrial waste by Psuedomonas aeruginosa. Int. J. Innov. Scientific Res. 3, 107-110.

Pérez-Arauz, A. O., Aguilar-Rabiela, A. E., Vargas-Torres, A., Rodríguez-Hernández, A. I., Chavarría-Hernández, N., Vergara-Porras, B., et al. (2019). Production and characterization of biodegradable films of a novel polyhydroxyalkanoate (PHA) synthesized from peanut oil. Food Packag. Shelf Life 20:100297. doi: 10.1016/j.fpsl.2019.01.001

Pillai, A. B., Kumar, A. J., Thulasi, K., and Kumarapillai, H. (2017). Evaluation of short-chain-length polyhydroxyalkanoate accumulation in bacillus aryabhattai. Braz. J. Microbiol. 48, 451-460. doi: 10.1016/j.bjm.2017.01.005

Ramsay, B. A., Lomaliza, K., Chavarie, C., Dubé, B., Bataille, P., and Ramsay, J. A. (1990). Production of poly-( $\beta$-hydroxybutyric-co- $\beta$-Hydroxyvaleric) acids. Appl. Environ. Microbiol. 56, 2093-2098. doi: 10.1128/aem.56.7.2093-2098. 1990
Randriamahefa, S., Renard, E., Guérin, P., and Langlois, V. (2003). Fourier transform infrared spectroscopy for screening and quantifying production of PHAs by pseudomonas grown on sodium octanoate. Biomacromolecules 4, 1092-1097. doi: $10.1021 / \mathrm{bm} 034104 \mathrm{o}$

Reddy, S. V., Thirumala, M., and Mahmood, S. K. (2008). Production of PHB and $\mathrm{P}$ (3HB-co-3HV) biopolymers by bacillus megaterium strain OU303A isolated from municipal sewage sludge. World J. Microbiol. Biotechnol. 25, 391-397. doi: 10.1007/s11274-008-9903-3

Ruiz, C., Kenny, S. T., Babu, P. R., Walsh, M., Narancic, T., and O'Connor, K. E. (2019). High cell density conversion of hydrolysed waste cooking oil fatty acids into medium chain length polyhydroxyalkanoate using Pseudomonas putida KT2440. Catalysts 9:468. doi: 10.3390/catal9050468

Sangkharak, K., and Prasertsan, P. (2008). Nutrient optimization for production of polyhydroxybutyrate from halotolerant photosynthetic bacteria cultivated under aerobic-dark condition. Electron. J. Biotechnol. 11, 83-94. doi: 10.2225/ vol11-issue3-fulltext-2

Shamala, T. R., Divyashree, M. S., Davis, R., Latha Kumari, K. S., Vijayendra, S. V. N., and Baldev, R. (2009). Production and characterization of bacterial polyhydroxyalkanoate copolymers and evaluation of their blends by Fourier transform infrared spectroscopy and scanning electron microscopy. Indian J. Microbiol. 49, 251-258. doi: 10.1007/s12088-009-0031-z

Singh, G., Kumari, A., Mittal, A., Yadav, A., and Aggarwal, N. K. (2013). Poly $\beta$-Hydroxybutyrate production by Bacillus subtilis NG220 using sugar industry waste water. Biomed, Res. Int. 2013:952641. doi: 10.1155/2013/952641

Singh, P., and Mahato, R. P. (2019). Screening of potential soil bacteria for detection of polyhydroxyalkanoate (PHA) accumulation. Int. J. Res. Advent Technol. 7, 1598-1604. doi: 10.32622/ijrat.73201984

Soberón-Chávez, G., Lépine, F., and Déziel, E. (2005). Production of rhamnolipids by Pseudomonas aeruginosa. Applied microbiology and biotechnology 68, 718-725.

Song, J. H., Jeon, C. O., Choi, M. H., Yoon, S. C., and Park, W. (2008). Polyhydroxyalkanoate (PHA) production using waste vegetable oil by pseudomonas sp. strain DR2. J. Microbiol. Biotechnol. 18, 1408-1415

Steinbüchel, A., Hustede, E., Liebergesell, M., Pieper, U., Timm, A., and Valentin, H. (1992). Molecular basis for biosynthesis and accumulation of polyhydroxyalkanoic acids in bacteria. FEMS Microbiol. Rev. 103, 217-230. doi: 10.1111/j.1574-6968.1992.tb05841.x

Sun, Z., Ramsay, J. A., Guay, M., and Ramsay, B. A. (2007). Fermentation process development for the production of medium-chain-length poly-3-hydroxyalkanoates. Appl. Microbiol. Biotechnol. 75, 475-478. doi: 10.1007/s00253-007-0857-4

Tamura, K., Stecher, G., Peterson, D., Filipski, A., and Kumar, S. (2013). MEGA6: molecular evolutionary genetics analysis version 6.0. Mol. Biol. Evol. 30, 2725-2729. doi: 10.1093/molbev/mst197

Tripathi, A. D., Yadav, A., Jha, A., and Srivastava, S. K. (2012). Utilizing of sugar refinery waste (cane molasses) for production of bio-plastic under submerged fermentation process. J. Polym. Environ. 20, 446-453. doi: 10.1007/s10924-011-0394-1

Tufail, S., Munir, S., and Jamil, N. (2017). Variation analysis of bacterial polyhydroxyalkanoates production using saturated and unsaturated hydrocarbons. Braz. J. Microbiol. 48, 629-636. doi: 10.1016/j.bjm.2017.02.008

Vassiliou, E. K., Gonzalez, A., Garcia, C., Tadros, J. H., Chakraborty, G., and Toney, J. H. (2009). Oleic acid and peanut oil high in oleic acid reverse the inhibitory effect of insulin production of the inflammatory cytokine TNF- $\alpha$ both in vitro and in vivo systems. Lipids Health Dis. 8:25. doi: 10.1186/1476-511X-8-25

Conflict of Interest: The authors declare that the research was conducted in the absence of any commercial or financial relationships that could be construed as a potential conflict of interest.

Publisher's Note: All claims expressed in this article are solely those of the authors and do not necessarily represent those of their affiliated organizations, or those of the publisher, the editors and the reviewers. Any product that may be evaluated in this article, or claim that may be made by its manufacturer, is not guaranteed or endorsed by the publisher.

Copyright (c) 2021 Mahato, Kumar and Singh. This is an open-access article distributed under the terms of the Creative Commons Attribution License (CC BY). The use, distribution or reproduction in other forums is permitted, provided the original author(s) and the copyright owner(s) are credited and that the original publication in this journal is cited, in accordance with accepted academic practice. No use, distribution or reproduction is permitted which does not comply with these terms. 